\title{
Comunicação
}

(Communication)

\section{Encontro do parasitóide Tachinaephagus zealandicus (Ashmead) (Hymenoptera: Encyrtidae) em pupas de Chrysomya megacephala (Fabricius) (Diptera: Calliphoridae) em carcaça de rato}

\begin{abstract}
[Occurrence of the parasitoid Tachinaephagus zealandicus (Ashmead) (Hymenoptera: Encyrtidae) in pupae of
\end{abstract} Chrysomya megacephala (Fabricius) (Diptera: Calliphoridae) in rat carcass]

\author{
T.C. Moretti, O.B. Ribeiro \\ ${ }^{1}$ Instituto de Biologia - UNICAMP \\ Caixa Postal 6109 \\ 13083-970 - Campinas, SP
}

Chrysomya megacephala (Fabricius, 1794) foi pela primeira vez observada no Brasil na década de 70 e dispersou-se rapidamente, atingindo todo o território nacional (Guimarães et al., 1978; Guimarães et al., 1979). Tem considerável importância médica e veterinária por atuar como vetor mecânico de patógenos, entre os quais protozoários (Greenberg, 1973), bactérias entéricas, como Shigella sp. e Salmonella sp. (La Paz, 1938) e helmintos, como Ascaris sp., Toxocara sp., Trichuris sp., Capillaria sp., oxiurídeos e tricostrongilídeos (Monzon et al., 1991; Oliveira et al., 2002), além de ser responsável por causar miíase secundária ( Leger e Couput, 1924).

Os adultos dessa mosca são atraídos por alimentos, fezes de origem humana e animal, depósitos de lixo, aterros sanitários e carcaça de animais. Além dos hábitos alimentares promíscuos, o grande tamanho e a grande quantidade de cerdas em seu corpo também constituem importantes fatores para a incriminação de C. megacephala como vetora mecânica de patógenos (Oliveira et al., 2002).

Atualmente, é considerada espécie eusinantrópica e cria-se com mais facilidade na área urbana, características que dificultam o controle químico, o qual pode representar perigo de contaminação ao homem, animais e ambiente. Nesse contexto, insere-se a possibilidade de utilização de microhimenópteros parasitóides no controle biológico de $C$. megacephala, por ser um método fácil, seguro e barato (Carvalho et al., 2003).

Tachinaephagus zealandicus (Ashmead, 1904) é uma espécie endoparasita gregária de larvas de dípteros superiores das famílias Calliphoridae, Sarcophagidae e Muscidae, comumente encontrada no hemisfério sul (Silveira et al., 1989). Johnston e Tiegs (1921) conduziram as primeiras investigações quanto à biologia desse microhimenóptero, envolvendo larvas de Calliphoridae provenientes de carcaças. Olton e Legner (1974) indicaram que as fêmeas de $T$. zealandicus são atraídas por material vegetal ou animal em decomposição.

O presente estudo relata a ocorrência do parasitóide $T$. zealandicus em pupas de $C$. megacephala associadas à carcaça de rato em área de formação vegetal secundária de $3.500 \mathrm{~m}^{2}$, no município de Campinas, SP $\left(22^{\circ} 49^{\prime} 15^{\prime}\right.$ 'S, $\left.47^{\circ} 04^{\prime} 08^{\prime}, \mathrm{W}\right)$. Objetiva-se disponibilizar tal informação para uso em controle biológico.

Expôs-se uma carcaça de rato (Rattus norvegicus, linhagem Wistar) de $251,75 \mathrm{~g}$ em 
local parcialmente ensolarado, dentro da área de estudo. A carcaça foi acondicionada em embalagem plástica $(15 \times 10 \times 10 \mathrm{~cm})$, cuja base foi retirada e substituída por uma tela de arame com malha reduzida entre nós, a qual permite fluxo de água, porém não permite a saída de imaturos de dípteros. Entre a tela de arame e a carcaça, foi colocada uma camada de $4 \mathrm{~cm}$ de vermiculita, material adequado para absorver a umidade proveniente da água da chuva. Uma armação de ferro $(30 \times 30 \times 30 \mathrm{~cm})$ revestida por tela de arame com malha de uma polegada entre nós foi fixada sobre a embalagem plástica, por meio de quatro ganchos de ferro, um em cada lado da base da gaiola, permitindo acesso de artrópodes, mas impedindo o acesso de animais carniceiros de grande porte. Durante o período de exposição da carcaça, parâmetros físicos foram medidos diariamente, sempre entre as 10 e 13 horas (Tab. 1). Após a decomposição total da carcaça, larvas e pupas foram retiradas da embalagem plástica exposta no ambiente e acondicionadas em pote plástico contendo vermiculita, substrato para pupariação das larvas. Esses potes foram mantidos no laboratório de entomologia sob temperatura de $25 \pm 1^{\circ} \mathrm{C}$ e umidade relativa de $60 \pm 10 \%$, para acompanhamento da emergência dos adultos.

Tabela 1. Estágios de decomposição de carcaça ${ }^{1}$ de ratos e dados meteorológicos do período de exposição

\begin{tabular}{lccccccc}
\hline $\mathrm{DE}$ & $\mathrm{ED}$ & $\mathrm{TA}\left({ }^{\circ} \mathrm{C}\right)$ & $\mathrm{T} \min \left({ }^{\circ} \mathrm{C}\right)$ & $\mathrm{Tmáx}\left({ }^{\circ} \mathrm{C}\right)$ & $\mathrm{UR}(\%)$ & $\mathrm{P}(\mathrm{mm})$ & $\mathrm{V}(\mathrm{km} / \mathrm{h})$ \\
\hline 1 & $\mathrm{I}$ & 31 & 19 & 31 & 65 & 6 & 20,3 \\
2 & $\mathrm{I}$ & 29 & 19 & 29 & 62 & 12 & 19 \\
3 & $\mathrm{P}$ & 27 & 20 & 30 & 66 & 1,7 & 17,5 \\
4 & $\mathrm{PE}$ & 23 & 18 & 23 & 78 & 9,6 & 31,5 \\
5 & $\mathrm{~S}$ & 27 & 16 & 31 & 59 & 7,6 & 6,4 \\
6 & $\mathrm{~S}$ & 25 & 18 & 33 & 52 & 0,2 & 14,7 \\
\hline
\end{tabular}

1: Bornemissza (1957).

$\mathrm{DE}=$ dias de exposição; $\mathrm{ED}=$ estágio de decomposição da carcaça: $\mathrm{I}=$ inicial; $\mathrm{P}=$ putrefação; $\mathrm{PE}=$ putrefação escura; $\mathrm{S}=$ seco; $\mathrm{TA}=$ temperatura ambiente média do dia; Tmax $=$ temperatura máxima do dia; Tmin = temperatura mínima do dia; UR $=$ umidade relativa média do dia; $\mathrm{P}=$ precipitação acumulada em 24 horas, até as $8 \mathrm{~h}$ do dia de cada observação; $\mathrm{V}=$ velocidade do vento no momento da coleta.

A carcaça se decompôs totalmente em seis dias, entre os dias seis e 11 de dezembro de 2003. Ao longo do período de 25 dias da retirada da carcaça do campo, houve emergência de espécimes representantes das famílias Calliphoridae, Sarcophagidae, Muscidae e Fanniidae. Após esse período, restaram 73 pupas nas quais não houve emergência de dípteros. Tais pupas foram transferidas para um pequeno recipiente de vidro para observação.

Cinco dias após a transferência, notou-se a emergência de 43 fêmeas e 24 machos do microhimenóptero identificado como $T$. zealandicus. O dimorfismo sexual foi evidente, principalmente pelas características da antena. Baseando-se no formato e volume dos tubérculos na região posterior do pupário e na distância entre peritremas (Amorim e Ribeiro, 2001), constatou-se que os 73 pupários eram da espécie C. megacephala. A taxa de parasitismo para esse hospedeiro foi 91,8\%. Foi possível notar que $T$. zealandicus é de comportamento gregário, mas não foi possível quantificar o número exato de parasitóides que emergiu de cada pupa.
Levantamentos realizados por Silveira et al. (1989) e Carvalho et al. (2003) relataram a ocorrência de $T$. zealandicus em pupas de Cochliomyia hominivorax (Coquerel) (Calliphoridae), C. megacephala e Syntesiomyia nudiseta (Wulp) (Muscidae).

Quanto ao segundo estudo, que trata especificamente de parasitóides do califorídeo $C$. megacephala, não há dados relativos à taxa de parasitismo, ou seja, houve apenas descrição de ocorrência. Pode-se afirmar que ainda faltam dados suficientes para concluir se $T$. zealandicus é ou não promissor alvo de programas de controle para moscas sinantrópicas. A duração dos ciclos de vida de $T$. zealandicus $( \pm 27$ dias) e C. megacephala ( $\pm 8 \frac{1}{2}$ dias) foi importante para que não se descartassem as pupas logo após o período referente ao ciclo de vida da mosca.

Segundo Marchiori et al. (1998), as áreas de matas são importantes locais de origem de parasitóides inimigos naturais de dípteros. É interessante notar que o presente estudo foi realizado em área de mata, porém com características secundárias e localizada dentro do 
perímetro urbano do distrito de Barão Geraldo, Campinas, São Paulo.

Uma questão importante no estudo de inimigos naturais de moscas sinantrópicas é o reconhecimento de quais fases do ciclo de vida do díptero estudado são vulneráveis a determinado parasitóide. Segundo Newman e Andrewartha (1930), T. zealandicus tem preferência por ovipor em larvas de moscas de terceiro instar. Isso permite inferir que o parasitismo no presente estudo deve ter ocorrido no campo, já que as larvas ficaram expostas no meio ambiente e só foram encaminhadas ao laboratório por ocasião da decomposição total da carcaça, quando a maioria das larvas já havia se transformado em pupas. Saber o local onde ocorreu o parasitismo é importante, por exemplo, quando se mantêm criações de moscas em laboratório.

Pode-se concluir que se fazem necessários estudos mais específicos quanto à biologia e ecologia local de T. zealandicus, com o intuito de incrementar programas de controle biológico de moscas sinantrópicas, tendo em vista a importância médico-veterinária de algumas espécies, e também a dificuldade de implementação de controle químico em certas regiões urbanas.

Palavras-chave: mosca, Tachinaephagus zealandicus, Chrysomya megacephala, carcaça de rato, Campinas

\begin{abstract}
This study reports the occurrence of Tachinaephagus zealandicus (Ashmead) (Hymenoptera: Encyrtidae) parasitizing pupae of Chrysomya megacephala (Fabricius) (Diptera: Calliphoridae) associated with a decomposing rat carcass in a secondary wood area in Campinas, SP. The parasitism rate was 91.8\%.
\end{abstract}

Keywords: fly, Tachinaephagus zealandicus, Chrysomya megacephala, rat carcass, Campinas

\section{REFERÊNCIAS BIBLIOGRÁFICAS}

AMORIM, J.A.; RIBEIRO, O.B. Distinction among the puparia of three Blowfly species (Diptera: Calliphoridae) frequently found on unburied corpses. Mem. Inst. Oswaldo Cruz, v.96, p.781-784, 2001.

BORNEMMISSZA, G.F. An analysis of arthropod sucession in carrion and the effect of its decomposition on the soil fauna. Austr. J. Zool., v.5, p.1-2, 1957.

CARVALHO, A.R.; MELLO, R.P.; D'ALMEIDA, J.M. Microhimenópteros parasitóides de Chrysomya megacephala. Rev. Saúde Pública, v.37, p.810-812, 2003.

DE LA PAZ, G.C. The bacterial flora of flies caught in foodstores in the city of Manila. Mon. Bull. Bureau Health, v.18, p.1-20, 1938.

GREENBERG, B. Flies and disease: biology and disease transmission. New Jersey: Princeton University, 1973. v.II, 447p.

GUIMARÃES, J.H.; PRADO A.P.; BURALLI, G.M. Dispersal and distribution of three newly introduced species of Chrysomya RobineauDesvoid in Brazil (Diptera: Calliphoridae). Rev. Bras. Entomol., v.23, p.245-255, 1979.

GUIMARÃES, J.H.; PRADO A.P.; LINHARES, A.X. Three newly introduced blowflies species in southern Brazil (Diptera: Calliphoridae). Rev. Bras. Entomol., v.22, p.53-60, 1978.

JOHNSTON, T.H.; TIEGS, O.W. On the biology and economic significance of the chalcid parasites of Australian sheep-maggot flies. Proc. R. Soc. Queensl., v.33, p.99-128,1921.

LEGER, A.; COUPUT, A. Nasomyiase à Chrysomya dux. Esch. Bull. Soc. Pathol. Exot., v.17, p.375, 1924.

MARCHIORI, C.H.; OLIVEIRA, A.T.; SCATOLINI, D. Ocorrência de espécies de Alysiinae (Hymenoptera: Braconidae) em áreas de mata nativa da região de Itumbiara, GO. Arq. Inst. Biol., v.65, p.43, 1998.

MONZON, R.B.; SANCHEZ, A.R.; TADIAMAN, B.M. et al. A comparison of the role of Musca domestica (Linnaeus) and Chrysomya megacephala (Fabricius) as 
mechanical vectors of helminthic parasites in a typical slum area of metropolitan manila. Southeast Asian J. Trop. Med. Public Health, v.22, p.222-228, 1991.

NEWMAN, L.J.; ANDREWARTHA, H.G. Blowfly parasite. The red- legged chalcid, Stenoterys fulvoventralis (Dodd). J. Dep. Agric. West. Aust., v.2, p. 89-95, 1930.

OLIVEIRA, V.C.; MELLO, R.P.; D'ALMEIDA, J.M. Dípteros muscóides como vetores mecânicos de ovos de helmintos em jardim zoológico, Brasil. Rev. Saúde Pública, v.36, p.614-620, 2002.

OLTON, G.S.; LEGNER, E.F. Biology of Tachinaephagus zealandicus (Hymenoptera: Encyrtidae), parasitoid of synanthropic diptera. Can. Entomol., v.106, p.785-800, 1974.

SILVEIRA， G.A.R.; MADEIRA， N.G.; AZEREDO-ESPIN, A.M.L. et al. Levantamento de microhimenópteros parasitóides de dípteros de importância médico-veterinária no Brasil. Mem. Inst. Oswaldo Cruz, v.84, supl. IV, p.505$510,1989$. 